\title{
The Need for an Adoption and Acceptance Framework for Mobile Digital Library Services
}

\author{
Sumayyah AL-Faresi, Nayna Patel \\ School of Information Systems, Computing and Mathematics \\ Brunel University \\ Uxbridge, UK
}

\begin{abstract}
Along with the rapid increase of smartphone ownership, mobile applications have increased and mobile digital library services have evolved. Yet, mobile digital library services are not among the frequently used services. Apparently, there is still a lack of adoption and acceptance of mobile digital library services among libraries and their users. It is critical to study the factors that influence the adoption and acceptance of such services. The proposed framework in this research will help in the process of determining factors affecting users' acceptance of mobile digital library services. An extended TAM model with 21 factors derived from five selected models was the base for designing the proposed framework. The newly designed framework is classified into three categories: interface characteristics, personal characteristics, and system characteristics.
\end{abstract}

\section{Introduction}

The rapid increase of smartphone ownership and use has had an impact on the demand for mobile applications and mobile services [33]. One of the newly developed mobile services is mobile digital libraries [43]. This is a service that enables additional access to library content [9]. It is a service that can help library services to be available anytime, anywhere, and enable any library to expand the number of their users [28, 43]. Furthermore, it is a service that allows libraries to provide the majority of their services, that are also available on the library's website (e.g. library hours, searching the library catalogue, and booking a study room), on a smartphone [12].

However, unfortunately mobile digital library services are limited to a few academic libraries in developed countries [8; 40; 58]. In addition, literature lacks a coherent framework for mobile

digital library services adoption and acceptance [8; 40; 58]. That might explain the limited number of mobile libraries, and determine factors causing the delay in mobile library acceptance. Therefore, it has been suggested that libraries are in need of a framework that would help in the process of developing a mobile digital library application and the selection of services [28]. A framework that would help libraries understand users' needs, and what may interfere with and delay their acceptance of such services, is also important [8].

The aim of this research is to design an adoption and acceptance framework for mobile digital library services. This is achieved by integrating several models from related areas, including: digital library and mobile services. An extended technology acceptance model (TAM), called the mobile digital library acceptance framework, will be developed by selecting factors from: digital library acceptance model [54], acceptance of digital library systems in developing countries [45], mobile services acceptance model [17], wireless mobile data services acceptance model [52], and mobile service model [25].

\section{Models contributing to the framework}

TAM, the extension of the theory of reasoned action (TRA) [13] appeared to be the most widespread and accepted in the information systems field. The TAM assumes that perceived usefulness and perceived ease of use are the main factors influencing intention and behaviour in the use of a new information system [12]. In that sense, if library users believe that using a mobile library service is free of effort and will enhance their work, they will tend to use that service. In order to locate factors that might affect the adoption and acceptance of mobile library services, several models were investigated in relation to TAM. Five models were selected and reviewed.

The following section provides a description of each model and summarises the relevant factors selected from each model.

\subsection{Digital library acceptance model}

Since both mobile libraries and library websites provide similar services [12], models focusing on digital library acceptance were a good source for finding relevant factors affecting the acceptance of mobile digital library services. Thong, Hang and Tam [54] added nine variables to the TAM framework and organised them into three categories: 
interface characteristics, organizational context, and individual difference (see Fig. 1).

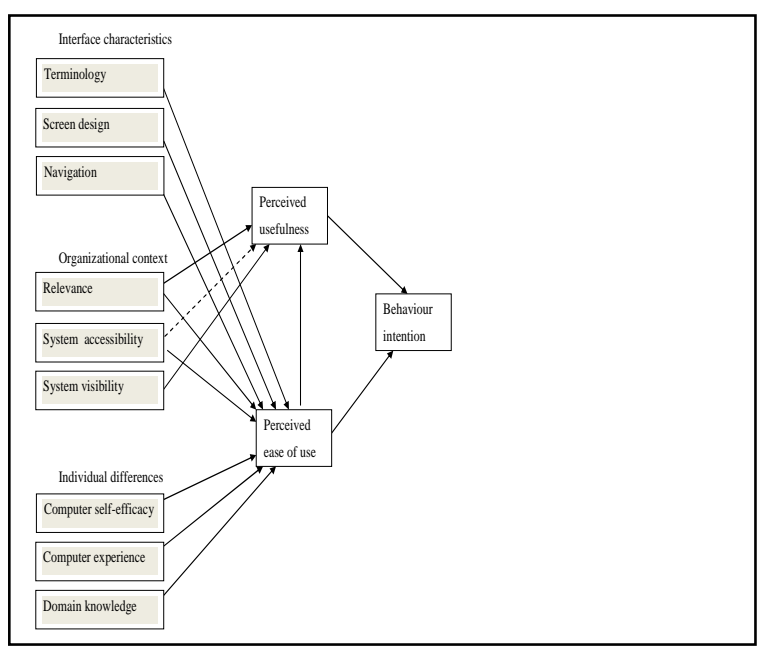

Figure 1. Digital library acceptance model [54]

These categories proved to have an impact on adoption intention through perceived usefulness and perceived ease of use of the digital library, specifically the Open University of Hong Kong. The same categories confirmed their impact on digital library acceptance in other studies as well. Lee et al.'s [32] study of Malaysian postgraduate students, Ramayah's [47] study of both postgraduate and undergraduate Malaysian students, and Jeong's [22] study of elementary students were all consistent with the findings of Thong, Hong and Tam's model [54]. The findings of that model showed that both perceived usefulness and perceived ease of use are determinants of user acceptance of digital libraries. Furthermore, interface characteristics and individual differences affected perceived ease of use, while organizational context (except for system accessibility) influenced both perceived ease of use and perceived usefulness of digital libraries. System accessibility had no significant impact on perceived usefulness, but had a strong impact on perceived ease of use.

Still the digital library acceptance model is far from covering important factors related to mobile services only. For that reason further mobile acceptance models will be investigated.

\subsection{Mobile service model}

Kargin, Basolgu and Daim [25] built a framework devoted to identifying factors affecting adoption of mobile services in general. The framework was tested on students using a location-based directory, Pocket Info \& Enjoy mobile service, which allows them to have phone numbers, address information, distance information, and taxi fee to a certain place. The framework covers several factors that the previously discussed digital library acceptance model does not cover. It consists of the following factors: image, personalization, content, mobility, enjoyment, innovativeness, and external influence (see Fig. 2).

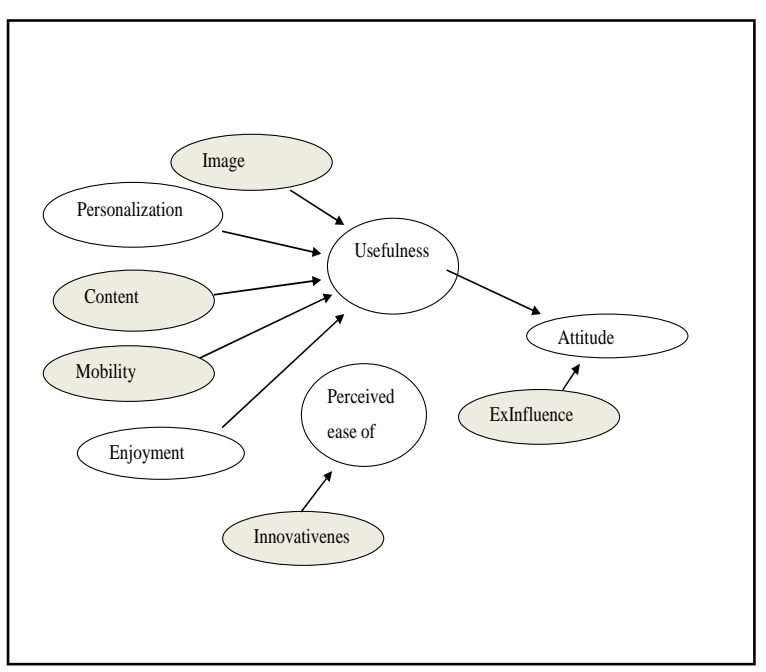

Figure 2. Mobile service model [25]

Image is the degree to which the use of the innovation or information system is perceived as enhancement of the user status in social system [9]. Personalization is a powerful tool that allows the users to select the content [25]. Mobility means having the ability to access resources from anywhere, anytime [25]. A personal initiative refers to the users' willingness to try out new applications or information technology [1]. External influence or social influence usually occurs when individuals have little or no experience of related innovation. They will tend to seek people's opinion.

The same factors were adopted in Phan's [46] study among university graduate students and professional workers, to find similar results. Mobility has a strong influence on usefulness. Content has a positive influence on usefulness. Innovativeness has a direct influence on ease of use. External influences have a positive influence on attitudes towards mobile services. Image is an important determinant in service usage as it positively and significantly influences the perception of usefulness. Personalization and enjoyment factors have a significant and positive influence on usefulness

\subsection{Mobile service acceptance model}

For the sake of understanding people's intention to use mobile services in the form of mobile applications in particular, Gao, Krogsite and Gransaether [16] proposed an extended model of TAM based on certain relevant factors, such as: context, trust, and personal initiatives and characteristics tested in a case study called the FindMyFriends system (see Fig. 3). 


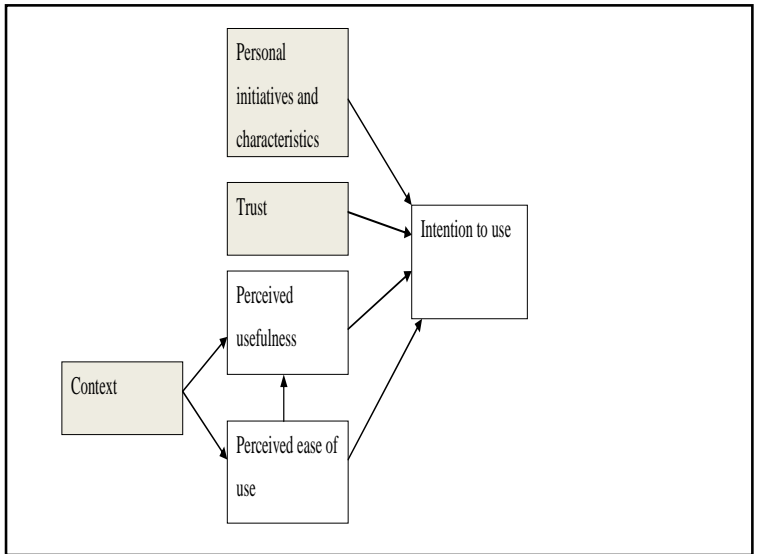

Figure 3. Mobile services acceptance model [16]

This is a system that allowed students to locate each other inside a particular building. Context like location, information history, and people conditions had a direct effect on both perceived usefulness and perceived ease of use, and an indirect effect on users' intentions [16]. In a sense this means that a mobile application may have a higher perceived usefulness when no desktop is available. The personal characteristics include: age, gender, background, knowledge and skills, culture, and preference [16].The trust factor can be defined as a user's belief or faith in the degree to which a particular mobile application has no security or privacy threats. Personal innovative and characteristics, and trust, had a direct effect on intention to use mobile applications [16].

Gao, Moe and Krogsite [17] used the mobile services acceptance model in a new case study called mobile student information systems (MSIS) for university students, to find consistent results with the previous FindMyFriends case [16]. Roine [49], Kuadey [30] and Moe [42] under Krogsite's supervision adapted the same model for the purpose of evaluating and testing usability of different mobile applications from different fields, such as: Mobile Tourism Recommender; MCLS - a prototype for elearning; and MSIS - a user-centric mobile app for the Norwegian University of Science and Technology. Their findings were consistent with Gao, Krogsite and Gransaether’s [16] findings.

\subsection{Wireless mobile data services acceptance model}

For the benefit of analyzing the adoption of wireless mobile services, Tan and Qi [52] combined both the TAM model and Hawkin's consumer behaviour model and tested them on students in China. Combining both TAM and Hawkin's model produced the following factors: perceived economy (PE), personal curiosity (PC), social influence (PSI, $\mathrm{SSI}$ ), and personal innovativeness to information technology (PIIT) (see Fig. 4).

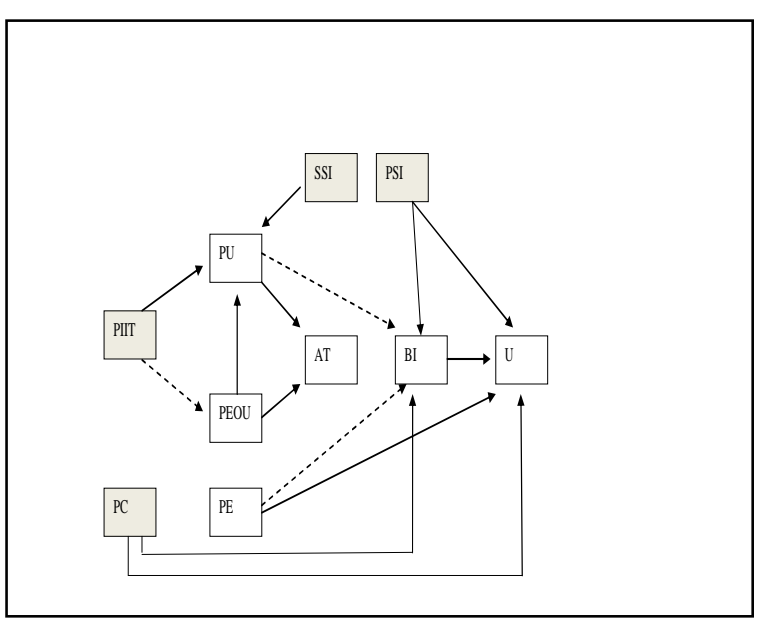

Figure 4. Wireless mobile data services acceptance model [52]

Perceived economy means when consumers think that the price of mobile service is costly, they will not use or intend to use the service, even if they believe it is useful or easy to use [52]. With people who do not have any or much knowledge and experience to help them form clear viewpoint, their curiosity not only greatly increases their insight into possible benefits, but also enhances their confidence in their ability to handle the technology under adoption [36]. Social influences are equal to subjective norm in TRA and refer to others' opinions, superior influences, and peer influences [53].

The findings of that research summarized into these points: perceived usefulness and perceived ease of use has a significant effect on attitude towards mobile service use. Perceived ease of use has a significant effect on perceived usefulness. Perceived economy has no effect on behavioural intention. Perceived economy has no effect on use. Personal innovativeness to information technology has a significant effect on perceived usefulness. Personal innovativeness to information technology has no effect on perceived ease of use. Perceived curiosity has a significant effect on behaviour intention. Perceived curiosity has a significant effect on the use. Superior social influence has a significant effect on perceived usefulness. Peer social influence has a significant effect on behaviour intention. And finally peer social influence has a significant effect on the use [52].

\subsection{Acceptance of digital library system in developing countries}

The objective of this research is to develop a framework suitable for all academic libraries. Yet, there might be some factors affecting mobile digital library acceptance among developing countries in particular. As developing countries are experiencing 
a rapid growth in mobile subscriptions [43], a framework that enables libraries in developing countries to catch up with developed countries in terms of e-learning and communication is needed. Based on that, choosing a model focusing on factors affecting the acceptance of digital libraries in developing countries is essential. The same factors might have the same influence on the adoption of mobile digital library service in developing countries.

Park et al.'s [45] model examines the factors that have a significant impact on people's adoption and use of digital library systems in the context of developing countries. Park et al. [45] concentrated on the same categories discussed earlier by Thong, Hong and Tam [54] excluding interface characteristics and including minor changes in individual differences and system/organizational characteristics. Park et al. [45] added three new factors to include English literacy, users' interest in publishing and conducting research, and library assistance through technical support (see Fig. 5).

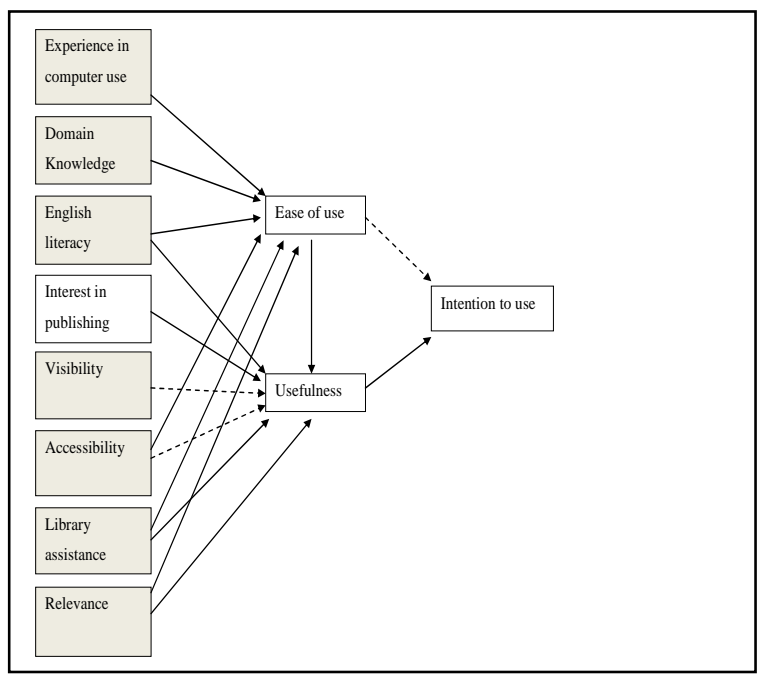

Figure 5. Acceptance of digital library system in developing countries [45]

Park et al. [45] found that English literacy had a direct effect on perceived ease of use and perceived usefulness, in addition to an indirect effect on behavioural intention to use. Interest in publishing factor also had a direct effect on perceived usefulness. Library assistance was also found to be a significant factor on both perceived ease of use and perceived usefulness. The rest of the findings were consistent with Thong, Hong and Tam [54] except for visibility. The more potential adopters can see an innovation used by peers, the more likely they are to use it [23]. Visibility of the system did not have any significant effect on perceived usefulness, contrary to Thong, Hong and Tam's model [54]. This might be related to the fact that only $2.1 \%$ of participants in that study had never used the system.

\section{Development of theoretical framework}

To study the acceptance of a mobile digital library service, a framework has been designed. Based on integrating the previously discussed models, 21 factors were organized into three categories: interface characteristics, personal characteristics, and system characteristics, to be tested and confirm their impact on mobile digital library services' adoption and acceptance.

\subsection{Interface Characteristics}

It is the medium between the system and the user [54]. Interface characteristics and user-centric system features such as menus, icons, and control tool bars enhance usability of any system [13; 11]. As a welldesigned interface contributes in reducing users' efforts to locate certain object on the screen, provides smooth navigation among screens, and makes the system looks more easy to use [15]. Based on that, this research believes that interface characteristics will enhance the usability of mobile digital library system and will interfere with their acceptance of such system.

3.1.1. Screen design. Screen design refers to the way information is presented on the screen [34]. A screen that is well organized and carefully designed assists users to scan the screen and locate relevant information more easily [54]. Therefore, screen clarity and organization are proposed to affect the acceptance of mobile digital library services.

3.1.2. Terminology. Terminology is a set of words, sentences, abbreviations or expressions used in a particular subject and reflected in a system [47]. A clear understanding of terminology decreases users' search efforts, facilitates efficient searching, and formulates easier digital library images [54]. The gap between the vocabulary of users and the professional terms and jargons of digital library providers [22] must be addressed, or if necessary accompanied by clear explanations, as it might affect search results [47]. Accordingly, clear terminology will affect the adoption and acceptance of a mobile digital library service.

3.1.3. Navigation. Navigation is the ease with which users can move around the system, understand menu options, and recognize where they are and where they are going in a sequence of screens [34]. By providing navigation aids or increasing the amount of unique landmarks, users can be prevented from getting lost in information-intensive systems, and guaranteed a sufficient search [34]. As a result of that, this research will propose that navigation clarity will help users find relative information on mobile 
digital library systems and prevent them from getting lost in it.

\subsection{Personal characteristics}

Personal characteristics describe the relationship between individual differences and information system [54] in this case mobile digital library system. Evaluating the usefulness of any information system evolved from evaluating the system itself toward evaluating its usefulness from user's perspective [3]. Just like any technological innovation, the success of mobile system depends as much on individual differences as on the technology itself [44]. As a matter of fact, Individual differences are the most significant determinants of Information system success [20;54] and digital library system success [6; 10]. It decides user performance on information retrieval systems [5; 10]. Therefore, this study believes that individual or personal characteristics will interfere with the acceptance and the success of mobile digital library system. The acceptance of mobile digital library may vary from individual to individual, depending on the characteristics of the individual.

3.2.1. Image. Users, who like to feel unique and recognizable in public because of their services, usually prefer to obtain the latest highly-advanced mobile phones and mobile services. Many people in China change their phones to show that they follow the latest trends and thus improve and maintain their social status [35]. Building on that, people who like to feel unique and want to enhance their image, will use a mobile digital library service.

3.2.2. Social Influence. Whenever an innovation creates uncertainty about its expected consequences for potential adopters, individuals feels uncomfortable and therefore tend to interact with social networks to consult on their adoption decisions [7]. Social influences can be divided into two variables: superior social influence that enhances perceived ease of use; and peer social influence that encourages consumer use without considering its usefulness or ease [52]. Research shows that the use of mobile search is heavily influenced by family and friends [25]. People may feel they should use a mobile search often after watching other people, even if they are not positive toward the behaviour or its consequences [57]. Following prior research, this study proposes that: the social network will have a major impact on the decision of mobile service use. Library users may feel they should use a mobile digital library service after they see their peers, friends, and teachers are using it.

3.2.3. Personal Innovativeness. Innovativeness refers to the user's willingness to try out new applications or information technology [1] or to the actual early adoption of new ideas, concepts, innovative products, or services related to other members of a society [48]. Innovative individuals are active information seekers about new ideas, who develop more positive intentions towards acceptance [48]. Personal innovativeness has significantly positive effects on both perceived ease of use and perceived usefulness [60]. So, innovative users will be willing to try out the new mobile digital library service.

3.2.4. English literacy. To read and understand information found on digital library systems, it is necessary to be literate about the language used in that system [45]. The more an individual understands articles written in English, the easier the person will find articles to use [45]. Similar to previous research, English literacy will affect the use of the mobile digital library system. The language used in the mobile digital library system is English too. The more a person is English literate, the more the person is going to use a mobile digital library service.

3.2.5. Mobility. Mobility means independence of time and place and having the ability to access from anywhere any time [25]. Mobility is significant to those who need real-time information and communication (i.e. work needs, emergency, communication, and contact). Mobility is also significant to those who need access in common situations, such as in car or on foot, without having to find a physical place, such as an office or internet café [38]. Thus, this research proposes that: the more mobile the user, the more valuable the mobile library service is to the user.

3.2.6. Mobile Self-efficacy. Bandura [2] defines self-efficacy as: people's judgments of their capabilities to organize and execute courses of action required to attain designed types of performance. It is concerned not with the skills one has but with the judgments of what one can do with whatever skills one possesses. From a library prospective, Miller and Khera [39] attached computer self-efficacy to the degree of self-ability to conduct a search on a library database or digital library. Individuals with higher levels of computer self-efficacy show stronger capabilities and confidence when using a computer, and in turn, require less support and assistance than those with less self-efficacy [26]. Therefore, this study believes that people with a high level of selfefficacy will be able to use and search on a mobile digital library system.

3.2.7. Mobile Experience. Computer experience can affect successful interaction with personal computers, the worldwide web, and information retrieval systems in libraries [21]. Prior experience 
with the internet also had a significant impact on the user's perception of digital libraries' usability or perceived ease of use [29]. In view of these findings, this research suggests that: years of mobile and smartphone experience can also affect the interaction with mobile digital library services.

3.2.8. Domain Knowledge. Domain knowledge is defined as the person's knowledge of a particular discipline, domain, or area that is relevant to the search [39]. Existing knowledge not only determines users' ability to understand the features and usage of an innovation [4], but also leads them into perceiving an innovation or a product similar to it to be less complex [51]. As a result, this research proposes that people who have solid knowledge in a particular discipline will understand the mobile digital library features. In addition, they will conduct better searches on a mobile digital library system.

3.2.9. Demographic Background. Personal characteristics include: age, gender, educational background, knowledge and skills, culture, and preference [16]. Different types of users have different attitudes and acceptance behaviour toward mobile commerce [41]. Accordingly, different types of users will act differently towards the acceptance of mobile digital library service. Their demographic background will shape their attitudes towards such service.

3.2.10. Trust. Trust can be defined as a user's belief or faith in the degree to which a specific mobile application can be regarded to have no security and privacy threats. In mobile applications there are two kinds of trust: trust in technology and trust in vendor. Trust in technology is dependent upon people's knowledge and experience of the technology. Trust in vendor primarily depends on people's perceptions of the vendor or service providers [16]. Trust is hard to gain but is easy to lose [17]. Thus, mobile digital library users should believe that this service is secured and protects their privacy.

3.2.11. Personal Curiosity. For people who do not have any or much knowledge and experience to help them form a clear viewpoint, their curiosity not only greatly increases their insight into possible benefits, but also enhances their confidence in their ability to handle the technology under adoption [36]. Therefore, this study believes that: curiosity can lead users towards adopting and accepting mobile digital library services.

\subsection{System Characteristics}

System characteristics focus on the interaction between the system and organizational context or the library [54]. Those factors are the technical support that facilitates access to the needed information [59]. They affect both user beliefs and the acceptance of technology in a variety of context $[13 ; 50]$. So in order to help the library succeed in delivering mobile digital library service, the design of the system should cover system characteristic factors. The design should be compatible, accessible, and visible to library users. Also the system should provide relevant up-to-date and correct information.

3.3.1. System Accessibility. System accessibility means easily locating specific computer systems, data and information [27]. If a digital library is difficult to access, either because of lack of computers or necessary software, users will tend to perceive it as difficult to use [54]. Thus, this research suggests that a mobile library system should be accessible whenever it is needed, otherwise people will not use it.

3.3.2. Relevance. Relevance refers to the degree to which the system matches the tasks carried out in the current environment [34]. Relevance in a library context mainly focuses on successfully delivering users' requests and matching their needs with the content in a digital library system [56]. Users' search efforts tend to be more productive and effective when they find relevant information in the digital library [54]. Relevant to them means locating useful documents [61]. In view of that, a mobile digital library system should have relevant resources to suit users' needs.

3.3.3. Library Assistance. The availability of technical support may enhance the rate of computer system acceptance [45]. Studies show that the ability to use a system among older adults and new users, who are less skilled in the use of the system or are developing searching skills, can increase through assistance [31]. Similar to previous studies, technical support may enhance the acceptance of mobile digital library services. Library users who are less skilled in using mobile services need mobile technical support.

3.3.4. Context. In the domain of mobile applications, the context can fall into two categories: first, the place-centered context, which refers to the location of people and the surrounding environment, and what kind of resources are available in that place; second, the people-centered context, that refers to the history of information that people maintain, the status and condition of the user, and the intention of the user [16].

Contextual information determines a user's decision on whether a mobile application is useful or easy to use [30]. For example, if people couldn't access a desktop computer, they will seek to access information systems via mobile devices in general 
[16]. In particular, when people cannot have access to library resources through a desktop computer, they will seek access through their mobile device. When a library service needs to be accessed immediately, regardless of time and place, a mobile digital library service will be the choice.

3.3.5. System Visibility. System visibility is the degree to which the results of an innovation are visible and communicable to others [48]. Visibility of a library system is particularly important for firsttime users [47]. The more potential adopters can see an innovation used by peers, the more likely they are to use it [14]. Accordingly, the visibility of a mobile digital library system is essential. Users should know that such a service exists.

3.3.6. Content. Content and content providers are key factors affecting users' adoption of any service, and a key barrier for attracting adopters [18]. Quality, correctness and delivery time of content are very sensitive matters [24]. Based on that, the quality and correctness of content should be considered in a mobile digital library service. Users should feel that library content provided through a mobile is sufficient.

3.3.7. Compatibility. Compatibility is not part of any previously-mentioned models, but it is an important factor that should be considered while studying mobile digital library acceptance. Compatibility is the degree to which an innovation is perceived as consistent with the existing values, past experiences, and needs of potential adopters (48). Karahanna, Agarwal and Angst [23] further defined compatibility into four distinct constructs: compatibility with preferred work style; compatibility with existing work practices; compatibility with prior experience; and compatibility with values. They found that compatibility beliefs had significant effects on perceived usefulness and perceived ease of use, as well as usage. Tornatzky and Klein [55] find perceived compatibility to be a crucial innovation characteristic driving consumer acceptance. Research also shows positive effects of perceived compatibility on both the attitude towards using a technology and its perceived usefulness [19], and that it has a direct impact on the intention to use technology [37]. If library users think that a mobile digital library service is compatible with their work style, with their beliefs, and with their experience, they will have the intention of using the service.

The following table summarizes the adopted factors, followed by a proposed framework (see Fig. 6).

\section{Framework contribution}

The proposed factors believed to have an impact on the adoption and acceptance of mobile digital library service should be considered as important factors in the process of designing, implementing, and operating a mobile digital library service.

Libraries wishing to implement a mobile digital library service should start doing so by considering the factors affecting the adoption and acceptance of a mobile digital library service. The newly designed framework will assist libraries designing a proper mobile digital library service that suits users' needs.

Moreover, the designed framework would help libraries investigating why library users decide to adopt a mobile digital library service, or leave after implementing. Having the ability to measure users' acceptance after implementing will enable future enhancement; and lead to users’ satisfaction.

\section{Conclusion}

The aim of this research is to design a framework for mobile digital library services adoption and acceptance. This has been achieved by integrating five models in relation to TAM. The newlydeveloped framework consists of 21 factors categorised into interface characteristics, personal characteristics, and system characteristics. The framework contributes to the understanding of users' adoption and acceptance of mobile digital library services. In addition, this framework will facilitate the process of designing and implementing a mobile library service. For future research, it would be fruitful to test this framework in several countries for global generalization of factors impacting on the adoption and acceptance of mobile digital library services. 
Figure 6. Proposed mobile digital library services adoption and acceptance

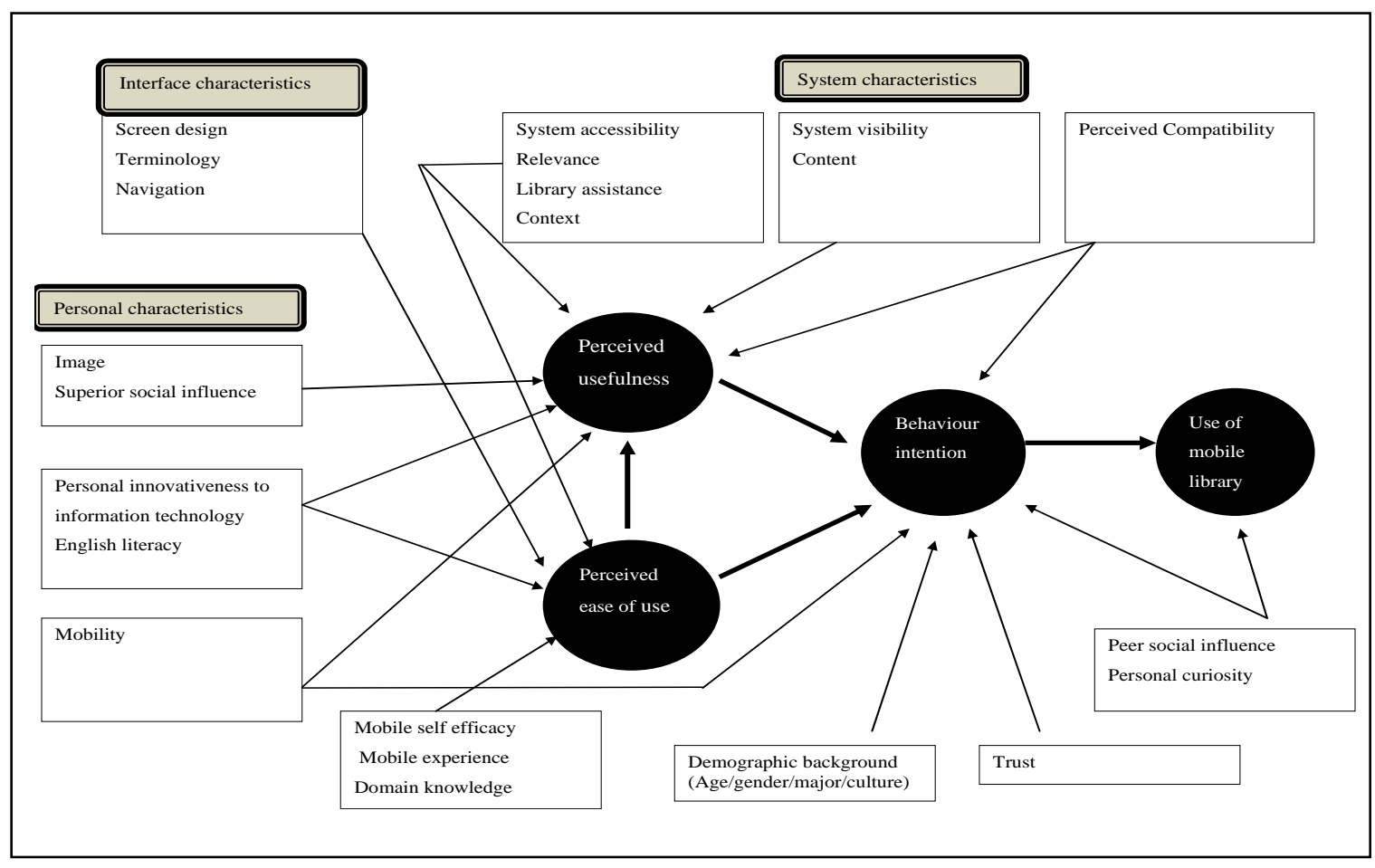

Table 1. Selected factors affecting mobile library acceptance

\begin{tabular}{|c|c|c|c|c|c|c|}
\hline \multirow{3}{*}{\begin{tabular}{l}
\multicolumn{1}{c}{ Models } \\
Digital library \\
acceptance model
\end{tabular}} & \multirow{3}{*}{\begin{tabular}{|l|}
\multicolumn{1}{|c|}{ Authors } \\
Thong, Hong and \\
Tam (2002)
\end{tabular}} & \multicolumn{5}{|c|}{ Factors } \\
\hline & & \begin{tabular}{|l|}
$\begin{array}{l}\text { Computer } \\
\text { self- } \\
\text { efficacy }\end{array}$ \\
\end{tabular} & Navigation & Terminology & $\begin{array}{l}\text { Screen } \\
\text { design }\end{array}$ & Domain knowledge \\
\hline & & \begin{tabular}{|l|}
$\begin{array}{l}\text { System } \\
\text { visibility }\end{array}$ \\
\end{tabular} & Relevance & \begin{tabular}{|l|}
$\begin{array}{l}\text { System } \\
\text { accessibility }\end{array}$ \\
\end{tabular} & $\begin{array}{l}\text { Computer } \\
\text { experience }\end{array}$ & $\begin{array}{l}\text { + TAM factors } \\
\text {-perceived ease of } \\
\text { use } \\
\text {-perceived usefulness } \\
\text {-behaviour intention } \\
\text {-use }\end{array}$ \\
\hline \multirow{2}{*}{$\begin{array}{l}\text { Acceptance of } \\
\text { digital library } \\
\text { systems in } \\
\text { developing } \\
\text { countries }\end{array}$} & \multirow[t]{2}{*}{\begin{tabular}{|l|} 
Park, et al. (2009) \\
\end{tabular}} & \begin{tabular}{|l} 
English \\
literacy
\end{tabular} & \begin{tabular}{|l|} 
Library \\
assistance
\end{tabular} & $\begin{array}{l}\text { Domain } \\
\text { knowledge }\end{array}$ & Visibility & $\begin{array}{l}\text { Experience in } \\
\text { computer use }\end{array}$ \\
\hline & & Relevance & Accessibility & $\begin{array}{l}\text { *Interest in } \\
\text { publishing }\end{array}$ & \multicolumn{2}{|c|}{$\begin{array}{l}\text { + TAM factors } \\
\text {-perceived ease of use } \\
\text {-perceived usefulness } \\
\text {-behaviour intention } \\
\text {-use }\end{array}$} \\
\hline \begin{tabular}{|l|} 
Mobile services \\
acceptance model
\end{tabular} & \begin{tabular}{|l|} 
Gao, Moe and \\
Krogsite (2010)
\end{tabular} & \begin{tabular}{|l} 
Context \\
\end{tabular} & Trust & $\begin{array}{l}\text { Personal } \\
\text { Initiatives and } \\
\text { characteristics }\end{array}$ & \multicolumn{2}{|c|}{$\begin{array}{l}\text { + TAM factors } \\
\text {-perceived ease of use } \\
\text {-perceived usefulness } \\
\text {-behaviour intention } \\
\text {-use }\end{array}$} \\
\hline $\begin{array}{l}\text { Wireless mobile } \\
\text { data services } \\
\text { acceptance model }\end{array}$ & Tan and Qi (2009) & \begin{tabular}{|l|}
$\begin{array}{l}\text { Social } \\
\text { influence }\end{array}$ \\
\end{tabular} & \begin{tabular}{|l|} 
Personal \\
innovativeness \\
to information \\
technology
\end{tabular} & $\begin{array}{l}\text { *Perceived } \\
\text { economy }\end{array}$ & $\begin{array}{l}\text { Personal } \\
\text { curiosity }\end{array}$ & $\begin{array}{l}\text { + TAM factors } \\
\text {-perceived ease of } \\
\text { use } \\
\text {-perceived usefulness } \\
\text {-behaviour intention } \\
\text {-use }\end{array}$ \\
\hline \multirow[t]{2}{*}{$\begin{array}{l}\text { Mobile service } \\
\text { model }\end{array}$} & \multirow[t]{2}{*}{$\begin{array}{l}\text { Kargin, Basoglu } \\
\text { and Daim (2009) }\end{array}$} & \begin{tabular}{|l} 
Image \\
\end{tabular} & Content & Mobility & \multicolumn{2}{|c|}{ Personalization } \\
\hline & & *Enjoyment & *ExInfluence & Innovativeness & \multicolumn{2}{|c|}{\begin{tabular}{|l|} 
+ TAM factors \\
-perceived ease of use \\
-perceived usefulness \\
-behaviour intention \\
-use \\
\end{tabular}} \\
\hline & $\begin{array}{l}\text { Bold ha } \\
\text { d factors } \\
\text { rk, while }\end{array}$ & used to & $\begin{array}{l}\text { the fram } \\
\text { model an } \\
\text { tot been u }\end{array}$ & $\begin{array}{l}\text { rk of this resea } \\
\text { o have been u }\end{array}$ & $\begin{array}{l}\mathrm{d}, \text { factors in } \\
d \text { in the }\end{array}$ & Italic \\
\hline
\end{tabular}




\section{References}

[1] Agarwal, R. \& Prasad, J. 1998, "A conceptual and operational definition of personal innovativeness in the domain of information technology", Information systems research, vol. 9, no. 2, pp. 204-215.

[2] Bandura, A. 1986, "Social foundations of thought and action: A cognitive social theory", Pretince Hall, Englewood Cliffs, New York.

[3] Barry, C. A. \& Squires, D. (1995). "Why the move from traditional information-seeking to the electronic library is not straightforward for academic users: some surprising findings”. In D. L. Raitt \& B. Jeapes, eds. Online Information 95: 19th International Online Information Meeting: Proceedings, pp. 177-187. London, December.

[4] Bauer, H.H., Reichardt, T., Barnes, S.J. \& Neumann, M.M. 2005, "Driving consumer acceptance of mobile marketing: a theoretical framework and empirical study", Main, vol. 6, no. 3, pp. 181-192.

[5] Borgman, C. L. (1987). "Toward a definition of user friendly: a psychological perspective”. In F. W. Lancaster, Ed. What Is User Friendly? Urbana-Champaign, IL: University of Illinois.

[6] Borgman, C. L. (1989). "All users of information retrieval systems are not created equal: An exploration into individual differences”. Information Processing and Management, 25 (3), 237-251.

[7] Burkhardt, M.E. \& Brass, D.J. 1990, "Changing patterns or patterns of change: The effects of a change in technology on social network structure and power", Administrative Science Quarterly, , pp. 104-127.

[8] Cao, Y., el al., 2006. "The Athabasca University mobile library project: increasing the boundaries of anytime and anywhere learning for students", Proceedings of the 2006 international conference on Wireless communications and mobile computing, pp. 1289-1294, ACM.

[9] Cao, Y., et al., 2008. An effective mobile- friendly digital library to support mobile learners. In: Needham, G. \& Ally, M., eds. 2008. M-libraries: libraries on the move to provide virtual access. Facet: London, pp.109-122.

[10] Chen, C., Czerwinski, M., \& Macredie, R. (2000). "Individual differences in virtual environmentsIntroduction and overview". Journal of the American Society for Information Science, 51 (6), 499-507.

[11] Cho, V., Cheng, T. C. E., \& Lai, W. M. J. (2009). “The role of perceived user-interface design in continued usage intention of self-paced e-learning tools”. Computers \& Education, 53, 216-227.

[12] Choy, F.C., 2011. "From library stacks to library-in-apocket: Will users be around?", Library Managemment, vol.32, no.1-2, pp.62-72.

[13] Davis, F.D. 1989, "Perceived usefulness, perceived ease of use, and user acceptance of information technology", MIS quarterly, pp. 319-340.

[14] Fishbein, M. \& Ajzen, I. 1975, Belief, attitude, intention and behaviour: An introduction to theory and research, AddisonWesley.

[15] Fox, E. A., Hix, D., Nowell, L. T., Brueni, D. J., Wake, W. C., Heath, L. S., et al. (1993). "Users, user interfaces, and objects: Envision, a digital library”. Journal of the American Society for Information Science, 44, 480-491.

[16] Gao, S., Krogstie, J. \& Gransæther, P.A. 2008, "Mobile services acceptance model", Convergence and Hybrid Information Technology, 2008. ICHIT'08. International Conference onIEEE, , pp. 446.

[17] Gao, S., Moe, S.P. \& Krogstie, J. 2010, "An Empirical Test of the Mobile Services Acceptance Model", Mobile Business and 2010 Ninth Global Mobility Roundtable (ICMB-GMR), 2010 Ninth International Conference onIEEE, , pp. 168.
[18] Gilbert, A.L. \& Han, H. 2005, "Understanding mobile data services adoption: demography, attitudes or needs?", Technological Forecasting and Social Change, vol. 72, no. 3, pp. 327-337.

[19] Hardgrave, B.C., Davis, F.D. \& Riemenschneider, C.K. 2003, "Investigating determinants of software developers' intentions to follow methodologies", Journal of Management Information Systems, vol. 20, no. 1, pp. 123-151.

[20] Harrison, A. W., \& Rainer, R. K. (1992). "The influence of individual differences on skill in end user computing”. Journal of Management Information Systems, 9 (1), 93-111.

[21] Igbaria, M., Guimaraes, T. \& Davis, G.B. 1995, "Testing the determinants of microcomputer usage via a structural equation model", Journal of Management Information Systems, vol. 11, no. 4, pp. 87-114.

[22] Jeong, H. 2011, "An investigation of user perceptions and behavioral intentions towards the e-library", Library Collections, Acquisitions, and Technical Services, vol.35, no. 2-3, pp.45-60.

[23] Karahanna, E., Agarwal, R. \& Angst, C.M. 2006, "Reconceptualizing compatability beliefs in technology acceptance research", Mis Quarterly, vol. 30, no. 4, pp. 781804.

[24] Kargin, B. \& Basoglu, N. 2006, "Adoption factors of mobile services", Mobile Business, 2006. ICMB'06. International Conference on IEEE, pp. 41.

[25] Kargin, B., Basoglu, N. \& Daim, T. 2009, "Factors affecting the adoption of mobile services", International Journal of Services Sciences, vol. 2, no. 1, pp. 29-52.

[26] Kim, Y.M. 2010, "Why should I use university library website resources? Discipline differences”, The Journal of Academic Librarianship, vol. 37, no. 1, pp. 9-18.

[27] Kling, R. \& Elliott, M. 1994, "Digital library design for organizational usability", ACM SIGOIS Bulletin, vol. 15, no. 2, pp. 59-70.

[28] Kroski, E., 2008. On the move with the mobile web: libraries and mobile technologies. In: Library Technology Reports, pp.1-48. Available at:http://www.alatechsource.org/ltr/onthe-move-with-the-mobile-web-libraries-and-mobiletechnologies

[29] Koohang, A. \& Ondracek, J. 2005, "Users’ views about the usability of digital libraries", British Journal of Educational Technology, vol. 36, no. 3, pp. 407-423.

[30] Kuadey, N. 2010, "Mobile Collaborative learning system”, Master thesis, Norwegian University of Science and Technology.

[31] Lam, J.C.Y. \& Lee, M.K.O. 2006, "Digital inclusiveness-Longitudinal study of Internet adoption by older adults", Journal of Management Information Systems, vol. 22, no. 4, pp. 177-206.

[32] Lee, G.T., Dahlan, N., Ramayah, T., Karia, N. \& Hasmi Abu Hassan Asaari, M. 2005, "Impact of interface characteristics on digital libraries usage", Malaysian Online Journal of Instructional Technology, vol. 2, no. 1, pp. 1-9.

[33] Liang, T.P. \& Wei, C.P., 2004. "Introduction to the special issue: mobile commerce applications", International Journal of Electronic Commerce, vol. 8, no. 3, pp. 7-17.

[34] Lindgaard, G. 1994, Usability testing and system evaluation: A guide for designing useful computer systems, Chapman \& Hall London, UK.

[35] Lu, J., Liu, C., Yu, C.S. \& Wang, K. 2008, "Determinants of accepting wireless mobile data services in China", Information \& Management, vol. 45, no. 1, pp. 52-64.

[36] Lu, J., Yao, J.E. \& Yu, C.S. 2005, "Personal innovativeness, social influences and adoption of wireless Internet services via mobile technology", The Journal of Strategic Information Systems, vol. 14, no. 3, pp. 245-268.

[37] Mallat, N., Rossi, M., Tuunainen, V.K. \& Oorni, A. 2006, "The impact of use situation and mobility on the acceptance of mobile ticketing services", System Sciences, 2006. 
HICSS'06. Proceedings of the 39th Annual Hawaii International Conference on IEEE, pp. $42 \mathrm{~b}$.

[38] May, P. 2001, Mobile commerce: opportunities, applications, and technologies of wireless business, Cambridge Univ Pr.

[39] Miller, J., Khera, O. 2010, "Digital library adoption and the technology acceptance model: a cross-country analysis", The Electronic Journal on Information Systems in Developing Countries, vol. 40, no. 6, pp. 1-19.

[40] Mills, K. \& Sheikh, H., 2010. "The Open University Library in Your Pocket", Journal of the Research Center for Educational Technology, vol. 6, no. 1, pp. 149-156.

[41] Min, Q., Ji, S. \& Qu, G. 2008, "Mobile commerce user acceptance study in China: a revised UTAUT model", Tsinghua Science \& Technology, vol. 13, no. 3, pp. 257-264.

[42] Moe, S.P. 2009, "Design and evaluation of a user-centric information system:Enhancing Student Life with Mobile Computing ", Master thesis, Norwegian University of Science and Technology.

[43] Needham, G. \& Ally, M., 2008. M-libraries: libraries on the move to provide virtual access, Facet, London.

[44] Nelson, D. L. (1990). "Individual adjustment to informationdriven technologies: A critical review”. MIS Quarterly, 14 (1), 79-98.

[45] Park, N., Roman, R., Lee, S. \& Chung, J.E. 2009, "User acceptance of a digital library system in developing countries: An application of the technology acceptance model", International Journal of Information Management, vol. 29, no. 3, pp. 196-209.

[46] Phan, K., Daim, T., Basoglu, N. \& Kargin, B. 2010, "Exploring technology acceptance across countries: case of mobile services adoption in the USA and Turkey", International Journal of Services Sciences, vol. 3, no. 2, pp. 216-231.

[47] Ramayah, T. 2006, "Doing e-research with e-library: Determinants of perceived ease of use of e-library", International Journal of Technology, Knowledge and Society, vol. 1, no. 4, pp. 71-82.

[48] Rogers, E.M. 2003, Diffusion of Innovations, $5^{\text {th }}$ ed,Free Press, NY.

[49] Roine, P.C. 2011, "Design and Evaluation of a personalized mobile tourist System”, Master thesis, Norwegian University of Science and Technology.

[50] Selim, H. M. (2003). "An empirical investigation of student acceptance of course websites". Computers \& Education, 40 (4), 343-360.

[51] Sheth, J.N. 1968, "Perceived risk and diffusion of innovations", Insights into consumer behavior, pp. 173-188.

[52] Tan, J., Qi, J. 2009, “An acceptance model of wireless mobile data services in china: combining TAM with consumer behavior model", Wireless communications, networking and mobile computing, 2009. WiCom'09. $5^{\text {th }}$ international conference on IEEE, pp.1-4

[53] Taylor, S. \& Todd, P. 1995, "Assessing IT usage: The role of prior experience", MIS quarterly, pp. 561-570.

[54] Thong, J.Y.L., Hong, W. \& Tam, K.Y. 2002, "Understanding user acceptance of digital libraries: what are the roles of interface characteristics, organizational context, and individual differences?", International Journal of Human-Computer Studies, vol. 57, no. 3, pp. 215-242.

[55] Tornatzky, L.G. \& Klein, K.J. 1982, "Innovation characteristics and innovation adoption-implementation: A meta-analysis of findings", IEEE Transactions on Engineering Management, vol. 29, no. 1, pp. 28-45.

[56] Vaidyanathan, G., Sabbaghi, A. \& Bargellini, M. 2005, "User acceptance of digital library: an empirical exploration of individual and system components", Journal of Computer Information Systems, vol. 6, no. 2, pp. 279-285.
[57] Venkatesh, V. \& Davis, F.D. 2000, "A theoretical extension of the technology acceptance model: Four longitudinal field studies", Management science, pp. 186-204.

[58] West, M.A., Hafner, A.W. \& Faust, B.D., 2006. "Expanding access to library collections and services using small-screen devices", Information technology and libraries, vol. 25, no. 2, pp. 103.

[59] Wilkinson, A., Forbes, A., Bloomfield, J., \& Gee, C. F. (2004). "An exploration of four web-based open and flexible learning modules in post-registration nurse education". International Journal of Nursing Studies, 41 (4), 411-424.

[60] Yang, K.C.C. 2005, "Exploring factors affecting the adoption of mobile commerce in Singapore", Telematics and Informatics, vol. 22, no. 3, pp. 257-277.

[61] Yao, Y. 1995, "Measuring retrieval effectiveness based on user preference of documents", Journal of the American Society for Information Science, vol. 46, no. 2, pp. 133-145. 